Case Report

\title{
Acute Compartment Syndrome of the Arm after Minor Trauma in a Patient with Optimal Range of Oral Anticoagulant Therapy: A Case Report
}

\author{
Paolo Titolo, Patrizia Milani, Bernardino Panero, Davide Ciclamini, \\ Giulia Colzani, and Stefano Artiaco
}

Department of Orthopaedics, Traumatology and Rehabilitation, AO Città della Salute e della Scienza, Orthopaedic and Trauma Center, Via Zuretti 29, 10126 Turin, Italy

Correspondence should be addressed to Paolo Titolo; paolotitolo@hotmail.com

Received 31 October 2013; Accepted 19 November 2013; Published 6 January 2014

Academic Editors: M. Domzalski and A. Papanikolaou

Copyright ( $\odot 2014$ Paolo Titolo et al. This is an open access article distributed under the Creative Commons Attribution License, which permits unrestricted use, distribution, and reproduction in any medium, provided the original work is properly cited.

Compartment syndrome of the arm is a rare event that can be subsequent to trauma or other pathological and physical conditions. At the arm the thin and elastic fascia may allow accumulation of blood more than in other districts, especially in patients undergoing anticoagulant therapy. We describe a rare case of an acute compartment syndrome of the arm after minor trauma with partial biceps brachii rupture in a patient with warfarin therapy and optimal value of INR. Prompt diagnosis and surgical decompression helped to avoid the occurrence of complications with a satisfying recovery of arm function.

\section{Introduction}

Compartment syndrome of the arm is rare. In most cases, it occurs after trauma [1,2], biceps or triceps rupture [3], subatmospheric pressure exposition [4], tourniquets application [5], shoulder dislocation [6], surgical complication [7], blood pressure cuff malpositions [8], injections [9], and venipunctures $[10,11]$.

Arm fascia is relatively thinner and more elastic compared to other anatomical districts. This creates more space for accumulation of blood. Variability of tolerance to increased intracompartmental pressure may influence clinical onset and the course of the syndrome [12,13].

Patients undergoing anticoagulant therapy raise their susceptibility to haemorrhage, and sometimes these drugs can facilitate the onset of an acute compartment syndrome. The relationship between acute compartment syndrome and warfarin treatment was first described by Hay et al. in 1992 in seven patients who sustained minor trauma in lower limbs (six cases) and forearm (one case) [14].

In this report, we describe a case of acute compartment syndrome of the arm after minor trauma with partial rupture of short head of biceps brachii in a patient undergoing warfarin therapy. To our knowledge this is the first case reported in the literature in which such kind of syndrome occurred in a patient with optimal value of INR.

\section{Case Report}

A 66-year-old right hand dominant woman reported minor shoulder trauma with arm elongation. She was assuming warfarin for 15 years after aortic valve replacement. At the time of hospital admission, she presented with pain and swelling at the right arm. A wide hematoma was present from the axillary region to the anteromedial side of the arm and the patient complained of limitation and pain of right upper arm during movements without vascular and nervous impairments. Laboratory values revealed increased levels of WBC $(12.5 \times 1000 / \mu \mathrm{L}), \mathrm{Hb} 13.2 \mathrm{~g} / \mathrm{dL}$, APTT $75.8 \mathrm{sec}, \mathrm{LDH} 735 \mathrm{UI} / \mathrm{L}$, CK $103 \mathrm{UI} / \mathrm{L}$, and INR of 3.0. Radiographs did not show fractures or dislocations. The ultrasound detected an intramuscular haematoma ( $3.5 \mathrm{~cm}$ in diameter, $15 \mathrm{~cm}$ in length) in the short head of biceps brachii without joint effusion.

Patient was admitted for monitoring and observation. Warfarin was stopped and low molecular weight heparin 
(LMWH) was given [15]. During the first day of observation the patient complained of increasing pain and laboratory exams showed further increase of WBC $(19.5 \times 1000 / \mu \mathrm{L})$ with INR 2. Two days after admission the ecchymosis was extended to the proximal third of the arm and radial and ulnar nerve palsy was observed. The median nerve was uninvolved and peripheral arterial pulses were present. The intracompartmental pressure measured with STRYKER 2952 QUICK PRESSURE MONITOR SET was $40 \mathrm{mmHg}$. Laboratory test values revealed $\mathrm{WBC} 20.6 \times 1000 / \mu \mathrm{L}, \mathrm{Hb} 11.8 \mathrm{~g} / \mathrm{dL}$, Hct 34.6\%, INR 1.41, APTT $41.8 \mathrm{sec}$ LDH $715 \mathrm{UI} / \mathrm{L}, \mathrm{CK}$ $736 \mathrm{UI} / \mathrm{L}$, myoglobin $540 \mathrm{ng} / \mathrm{mL}$.

Surgical treatment was planned with fasciotomy and drainage of haematoma through a deltoid-pectoral approach extended to the medial part of the upper arm. At the opening of brachial fascia, muscles appeared strained and compressed. The septum among brachialis and biceps muscle was opened and the haematoma was drained. Wound was closed with interrupted suture and a noncompressive bandage was applied. Postoperative therapy was prescribed giving disodium phosphate betamethasone, L-acetyl carnitine, paracetamol, and tramadol.

One day after surgery laboratory values revealed decreased WBC $(12.6 \times 1000 / \mu \mathrm{L})$, INR 1.13, APTT 29.6, myoglobin $334.70 \mathrm{ng} / \mathrm{mL}$. During postoperative period the patient started rehabilitation program. When the patient was discharged, he presented with limitation of hand and fingers movements and numbness for residual involvement of the ulnar nerve.

Four months after surgery, the patient showed almost complete triceps function (4/5 according to Medical Research Council scale) and full recovery of elbow flexion and wrist and finger motion. Sensibility was normal with two-point discrimination test value less than $5 \mathrm{~mm}$. Residual stiffness of the shoulder in abduction and external rotation was observed.

One year after surgery electroneurography showed normal radial, median, and ulnar nerves function and the patient reported a slight residual fatigue in the activity of daily living.

\section{Discussion}

Patients undergoing anticoagulant therapy raise their susceptibility to haemorrhage and are more exposed to development of an acute compartment syndrome.

Acute compartment syndrome after biceps brachii ruptures has been described in the literature in two patients with uncontrolled high INR value secondary to anticoagulant therapy. Richards reported a case of biceps long head rupture resulting in an upper arm compartment syndrome associated with nerve palsies in a patient who presented with INR value of 7.1 at hospital admission [16]. Another case of acute arm compartment syndrome was reported by Fung in a patient with biceps tendon rupture and an INR of 6.5 at time of clinical observation [17]. Only one compartment syndrome of the arm following minor trauma was previously reported in the literature in a patient assuming warfarin [18]. In our patient, the syndrome was diagnosed two days after trauma although the INR value was in controlled therapeutic range.
In patients with warfarin therapy, the risk of development of compartment syndrome should be always considered and prolonged clinical observation should be indicated in order to detect initial clinical symptoms. Early treatment with fasciotomy may prevent major complications and residual deficits.

\section{Conflict of Interests}

The authors declare that there is no conflict of interests regarding the publication of this paper. The patient was informed that data concerning the case would be submitted for publication.

\section{References}

[1] A. Antebi and D. Herscovici Jr., "Acute compartment syndrome of the upper arm: a report of 2 cases," The American Journal of Orthopedics, vol. 34, no. 10, pp. 498-500, 2005.

[2] N. H. Jenkins and W. J. Mintowt-Czyz, "Compression of the biceps-brachialis compartment after trivial trauma," Journal of Bone and Joint Surgery B, vol. 68, no. 3, article 374, 1986.

[3] R. J. Brumback, "Compartment syndrome complicating avulsion of the origin of the triceps muscle. A case report," Journal of Bone and Joint Surgery A, vol. 69, no. 9, pp. 1445-1447, 1987.

[4] E. M. Bluman, R. Z. Tashjian, P. F. Graves, and T. B. Hughes, "Subatmospheric pressure-induced compartment syndrome of the entire upper extremity: a case report," Journal of Bone and Joint Surgery A, vol. 86, no. 9, pp. 2041-2044, 2004.

[5] T. L. Greene and D. S. Louis, "Compartment syndrome of the arm-a complication of the pneumatic tourniquet. A case report," Journal of Bone and Joint Surgery A, vol. 65, no. 2, pp. 270-273, 1983.

[6] C. Y. Yen, W. L. Yeh, and Y. K. Tu, "Inferior dislocation of the glenohumeral joint combined with the compartment syndrome of the upper arm: case report," Changgeng Yi Xue Za Zhi, vol. 21, no. 3, pp. 358-361, 1998.

[7] B. L. Zhu, R. Zhao, R. B. Li, X. Wu, D. W. Guan, and G. H. Zhang, "Fatal acute compartment syndrome in patients after surgical treatment: 2 case reports," Legal Medicine, vol. 11, supplement 1, pp. S5444-S5445, 2009.

[8] B. M. Cascio, D. B. Pateder, J. H. Wilckens, and F. J. Frassica, "Compartment syndrome: time from diagnosis to fasciotomy," Journal of Surgical Orthopaedic Advances, vol. 14, no. 3, pp. 117121, 2005.

[9] I. Bala, M. Pratap, D. Nakra, and T. Ramprabhu, "Prolonged cholinergic crisis and compartment syndrome following subcutaneous injection of an organophosphate compound for suicide attempt," Journal of Forensic and Legal Medicine, vol. 15, no. 4, pp. 256-258, 2008.

[10] R. J. Roberge and M. McLane, "Compartment syndrome after simple venipuncture in an anticoagulated patient," Journal of Emergency Medicine, vol. 17, no. 4, pp. 647-649, 1999.

[11] D. B. Willsey and R. A. Peterfreund, "Compartment syndrome of the upper arm after pressurized infiltration of intravenous fluid," Journal of Clinical Anesthesia, vol. 9, no. 5, pp. 428-430, 1997.

[12] F. A. Matsen III, K. A. Mayo, R. B. Krugmire Jr., G. W. Sheridan, and G. H. Kraft, "A model compartmental syndrome in man with particular reference to the quantification of nerve 
function," Journal of Bone and Joint Surgery A, vol. 59, no. 5, pp. 648-653, 1977.

[13] F. A. Matsen III, R. A. Winquist, and R. B. Krugmire Jr., "Diagnosis and management of compartmental syndromes," Journal of Bone and Joint Surgery A, vol. 62, no. 2, pp. 286-291, 1980.

[14] S. H. Hay, M. J. Allen, and M. R. Barnes, "Acute compartment syndromes resulting from anticoagulant treatment," The British Medical Journal, vol. 305, no. 6867, pp. 1474-1475, 1992.

[15] J. Ansell, J. Hirsh, E. Hylek, A. Jacobson, M. Crowther, and G. Palareti, "Pharmacology and management of the vitamin $\mathrm{K}$ antagonists: American college of chest physicians evidencebased clinical practice guidelines (8th edition)," Chest, vol. 133, no. 6, supplement, pp. 160S-198S, 2008.

[16] A. M. Richards and A. L. H. Moss, "Biceps rupture in a patient on long-term anticoagulation leading to compartment syndrome and nerve palsies," Journal of Hand Surgery (European Volume), vol. 22, no. 3, pp. 411-412, 1997.

[17] D. A. Fung, S. Frey, and R. B. Grossman, "Rare case of upper arm compartment syndrome following biceps tendon rupture," Orthopedics, vol. 31, no. 5, article 494, 2008.

[18] F. S. Fadel and S. Benyahia, "Compartment syndrome in upper arm in anticoagulant therapy after minor trauma," Ugeskrift for Laeger, vol. 172, no. 31, pp. 2149-2150, 2010. 


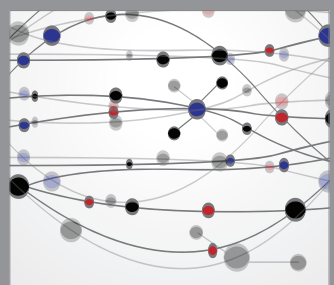

The Scientific World Journal
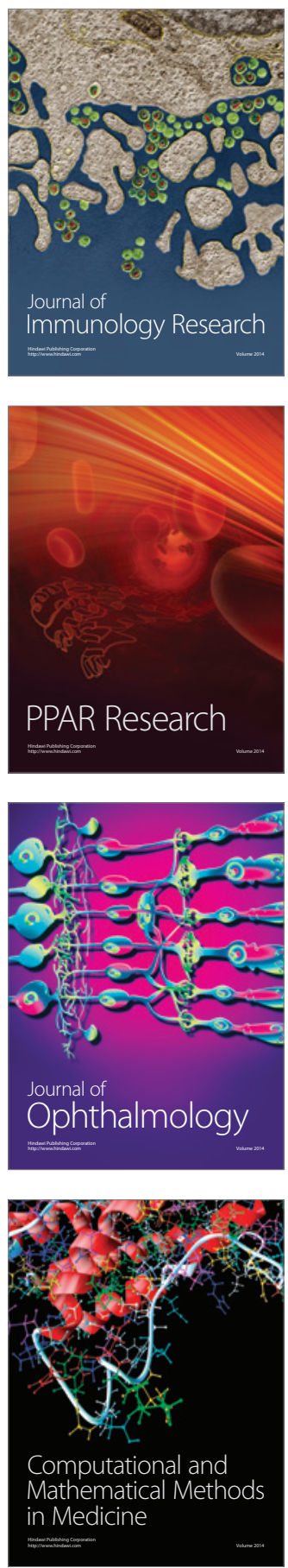

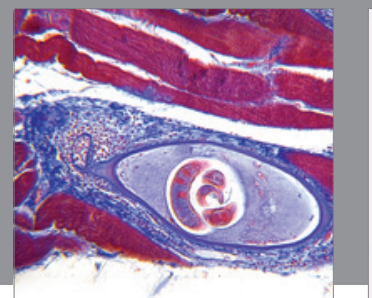

Gastroenterology

Research and Practice
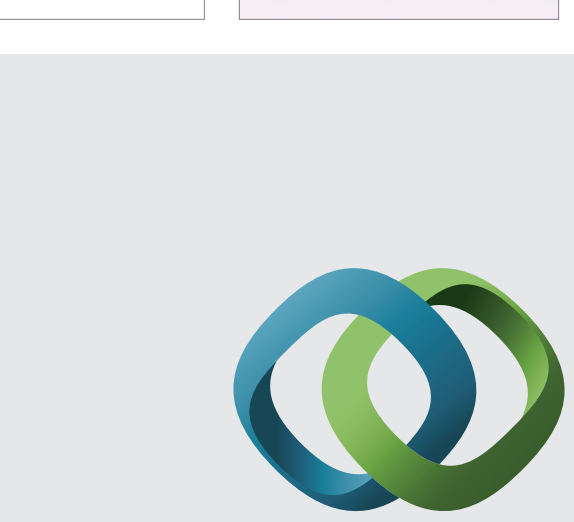

\section{Hindawi}

Submit your manuscripts at

http://www.hindawi.com
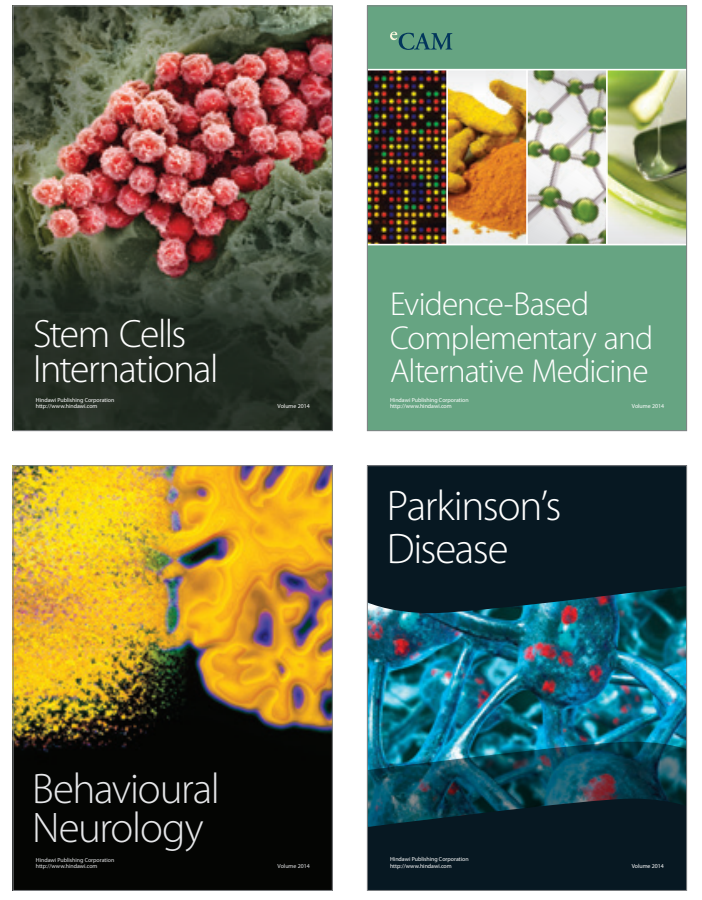
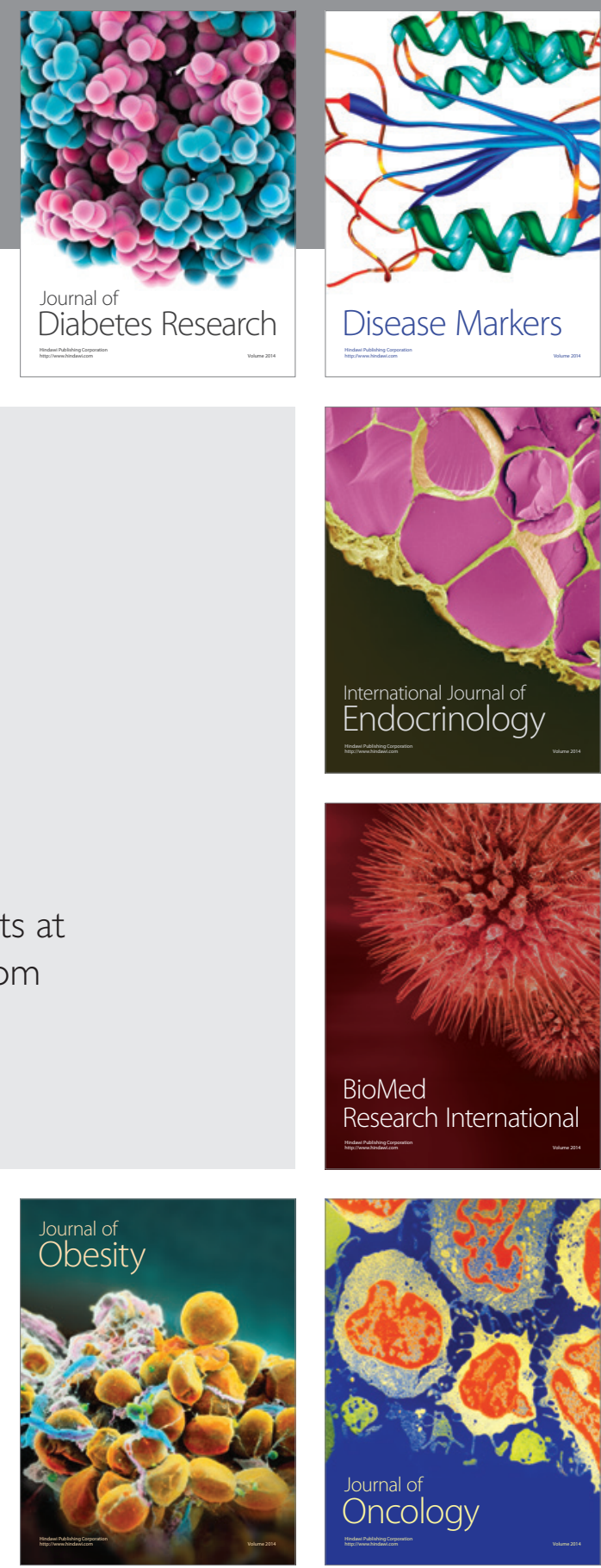

Disease Markers
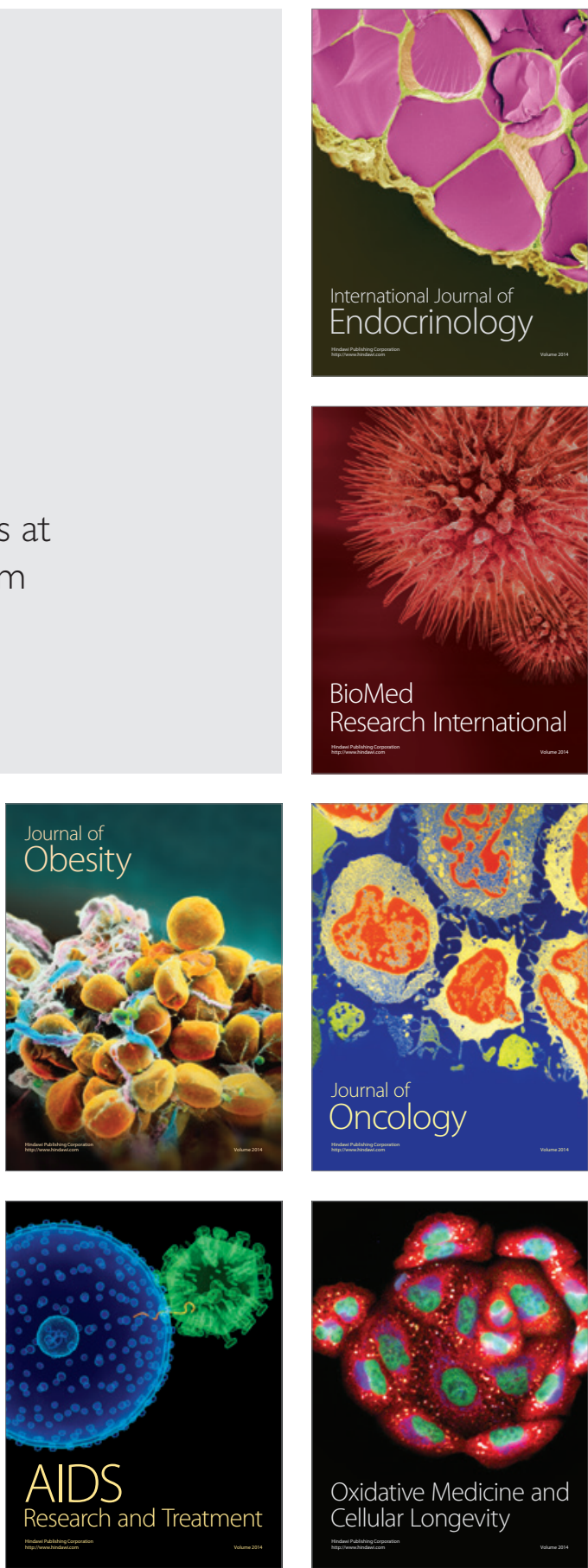